\title{
Patchworking Library Services for Invisiblized Youth
}

\author{
Rae-Anne Montague, Chicago State University, USA \\ Joseph A. Coyle, University of Illinois at Urbana-Champaign, USA
}

\begin{abstract}
Librarians find themselves continuously challenged to provide a growing range of innovative services. In order to succeed, this complex task is grounded in local context and implemented based on the needs of users, be it students, patrons, clients, or community members. This article considers parameters of and discusses strategies for developing library services to meet the needs of incarcerated youth. How can librarians be effective in serving these young people who have been drawn into atypical realms, away from their communities, away from the Internet? There is a clear and urgent need to provide excellent library services to the approximately 60,000 youth incarcerated across the U. S. Currently, there are groups that emphasize services to these users. For example, Library Services for Youth in Custody (LSYC) is a professional interest group that focuses on providing a network to support these services. Other agencies are also involved, often as part of outreach programs, special projects, or on an ad-hoc basis. Together, these efforts result in a patchwork of services. In this case study, we draw on the experience of several dedicated individuals and groups that work to form a patchwork for building awareness, sharing resources, and meeting the informational needs of incarcerated youth. We critically consider these matters in theory and practice while reflecting back on the ten years of providing library services at a youth detention facility located in the U.S. Midwest; like many similar facilities, it has no librarian, no other library staff, and no regular library budget.
\end{abstract}

Keywords: collaboration; incarceration; outreach; prison; youth

Publication Type: special section publication

\section{Critical Considerations}

A re we willing to relegate ever larger numbers of young people from racially oppressed communities to an isolated existence marked by authoritarian regimes, violence, disease, and technologies of seclusion that produce severe mental instability? Before we and others interested in supporting youth who are incarcerated consider ways to address this question, we must first step back and reflect on our privileged spheres as professionals and academics, and with what we are becoming involved. This initial question is derived from Angela Davis' seminal work, Are Prisons Obsolete? (2003). This is where we must begin.

As prison abolitionists, we believe in a different future, one "in which vital needs like housing, education, and health care, are met, allowing people to live safe and fulfilled lives-without the need for prisons" (Washington, 2018, para. 8)-or for prison library services. It is from this standpoint that we discuss the critical need for services for young people in carceral spaces that do not follow the logic of prison reform but are rather invested in building a radically different world. This new environment must exist beyond historical and contemporaneous 
inequities-where young people are not subjected to systems of control or invisibilized, but are rather situated in strong networks of support that celebrate their lives. There is much to do.

Prisons do not exist in a vacuum. They are embedded in a larger society and reflect problems therein. For example, although many consider the U.S. to be a wealthy nation, poverty remains widespread. Poverty and other disparities are rooted in historical and contemporaneous inequities that will be perpetuated without radical intervention. The status quo leaves those most vulnerable to suffer most (Fine \& Ruglis, 2009). In addition to economic inequity, the U.S. leads the world in incarceration rates. As noted by Wagner and Sawyer at the Prison Policy Initiative, the American criminal justice system holds almost 2.3 million people in numerous facilities including state and federal prisons, juvenile correctional centers, local jails, military prisons, immigration detention facilities, and psychiatric hospitals (2018).

Incarceration disproportionately affects young people, and racial and ethnic minorities. For example, Blacks make up $12 \%$ of the country, but $33 \%$ of the prison population-compared to Whites who account nationally for $64 \%$ and $30 \%$ in prison. The incarceration rate for African Americans is nearly five times the rate for Whites, and currently, almost $9 \%$ of all African American men are behind bars (Wagner \& Sawyer, 2018). The deleterious effects of incarceration must be understood as existing within a larger system of racial inequality. As Cacho (2012) describes, racialized and criminalized young people are often treated as though they lack full personhood. Youth who occupy this space are understood as potentially criminal by default. Targeted in this way, youth are disenfranchised from full eligibility to civil and human rights.

Incarceration is deeply rooted in historical inequity, and modern circumstances mirror past realities. For example, once a person is legally considered a felon, old forms of discrimination in employment, housing, voting, education, public benefits, and exclusion from jury service become legal once more (Alexander, 2010). There is a critical need to reduce these cycles of trauma and provide effective support to the millions of people who are involved in these tragic cycles across the nation.

\section{Angles of Intervention}

What does all of this mean for librarians? What possible interventions may be made by information professionals? In 2017, the Public Library Association published a book in its Quick Read for Busy Librarians series which offers librarians some initial approaches to serving incarcerated populations. This text provides a useful introduction to these services, but there is much more to consider and act upon. After discussing key topics and sharing some informative examples, the author, Nick Higgins (2017), poses two insightful questions that serve to advance this discussion: What power do we have as librarians to dismantle systems of oppression and, more importantly, how do we use that power once we realize we possess it?

In the context of juvenile detention librarianship, the possibilities vary greatly and are dependent on the location and the facility. Juvenile detention is mainly managed by states, and there are tremendous differences from state to state (National Institute of Corrections, 2015). Regardless of the specific location, as the American Civil Liberties Union (ACLU) describes, "confining young people-cutting them off from their families, disrupting their educations, and often exposing them to further trauma and violence-harms their development and has lifelong negative consequences" (2018, para. 1). 
What, then, may be effective roles and practices for librarians in this challenging time and space? In our experience working as librarians to support incarcerated youth over the past decade, we have observed an overall lack of awareness and commitment to providing resources. This is not surprising because people who are incarcerated are removed from society. At this time in history, however, there is no good excuse for librarians and other informed community members to ignore these oppressive circumstances.

As noted above, juvenile detention facilities vary in size and approach to services, however, we have yet to encounter any with a well-equipped library that is able to achieve highly effective standards. While federal and state statistics are lacking, it is safe to say that only a small percentage of juvenile detention facilities have any library staff at all. Large facilities, such as those located in urban areas like the Cook County detention center in Chicago are the exception. Large facilities tend to align with the model of school librarianship in providing services. However, library capacities may be limited based on the constraints of the facility. For example, libraries may lack resources, have limited scheduling possibilities, and be unable to provide Internet access. Given these constraints, they are usually unable to consistently achieve effective outcomes or move toward progressive, holistic, or sustainable services, such as those described by Austin (2018).

\section{Patchwork Model}

With limited time, space, and other resources, how then do the majority of juvenile detention centers (JDCs) provide library services? The sad fact is that many simply do not offer them. For the majority of smaller facilities outside of urban hubs, there are few or no designated library staff or resources. In order to provide any sort of collections or programming, library services often take the form of patchworks of support. Individuals and organizations, often with very limited resources or formal training in library and information science, form partnerships that fluctuate over time. Patchworks of support are often ridden with uncertainty because it is never clear when institutional support will be provided and for how long it will last.

There is nothing romantic about a patchwork approach. These support networks are a consequence of systematic disinvestment in dynamic social programs that support the needs and interests of youth. As Anna Tsing (2015) writes, however, "to appreciate the patchy unpredictability associated with our current condition, we need to reopen our imagination" ( $p$. 5). Thus, what follows is a variety of approaches we have drawn upon ourselves as we have attempted to account for various levels of library support and to consider possible alternatives.

As Sweeney (2011) notes, there is a clear need to provide basic library services, such as reading opportunities, access to information, and research skill development to at-risk youth. However, providing library services without staff, budget, or organizational affiliation to young people who are facing onerous systematic challenges is a complex endeavor. There is no singular or simple path. In the following sections, we share a patchwork of sources and approaches we have found useful in terms of three main areas-networks, collections, and programs.

\section{Networks}

Library Services for Youth in Custody (LSYC; http://www.youthlibraries.org) is an interest group of the Association of Specialized and Cooperative Library Agencies, a division of the American Library Association that focuses on providing a network to support these endeavors. LSYC supports librarians that work with youth in custody including incarcerated, detained, and 
committed youth in a variety of juvenile and adult settings as well as mental health facilities and group-homes. LSYC provides access to a network of dedicated professional peers who are available to offer advice and encouragement and to share experiences. Much of this takes place on the group listserv. From time to time, there are also opportunities to meet up in person at conferences or other professional gatherings.

Peer support also comes from local librarians and information studies students, as well as through alliances with community organizations that develop through shared interests and goals. Detention center staff, especially teachers, who care about the youth and understand educational goals and institutional norms, are essential in terms of providing access, considering possibilities, and supporting day-to-day library operations.

As much as possible, it is important that library services be structured in ways that draw upon the knowledge of people with personal experience with incarceration. We have collaborated with both formerly incarcerated youth and currently incarcerated adults to develop and offer library programming and services. For example, our writing program was informed by feedback provided by an incarcerated author. We also made efforts to include materials by other currently or formerly incarcerated individuals. These texts, often non-published or selfpublished, are among the most popular.

While each state or facility may have rules that limit certain types of collaboration, librarians involved in providing services to youth who are incarcerated should look for options to involve those with lived experience. Connecting with groups such as Ex-Cons for Community and Social Change (ECCSC; https://www.eccsc.info) is a good place to begin. ECCSC is a coalition with hundreds of formerly incarcerated individuals who have taken on the responsibility to serve their local communities.

Over the course of our involvement, local networks of support shifted regularly, based on the dynamic nature of the organizations. On the one hand, this shifting led to some limitations in terms of continuity; on the other, it often brought in new energy. The ability to draw on diverse networks has been essential to building and improving the collection and providing engaging programs.

\section{Collections}

Considering collection development, it is important that we re-emphasize critical awareness. To do this, we had to step back and reflect on our position of privilege in these endeavors and to consider Tatum's (2006) work in the context of resource development. Tatum underscores the importance of culturally-conscious information, which increases potential for interest and counters power imbalances pervasive across educational systems. This grounding is echoed by contemporary library initiatives such as We Need Diverse Books (WNDB) and In the Margins.

According to their website, WNDB is "a grassroots organization of children's book lovers" that aims "to produce and promote literature that reflects and honors the lives of all young people" (2018, para 1). The WNDB website includes many helpful resources for finding diverse books, recommendations for summer reading, and writing diversely. WNDB also sponsors a number of innovative programs, such as the Walter Grant, to support diverse unpublished authors and illustrators, internship and mentorship initiatives, free visits to schools, and a mobile app called OurStory. The WNDB blog is filled with thoughtful insights from authors and other reading, writing, and viewing enthusiasts. 
In the Margins is a committee consisting of "librarians who currently work or have recently worked with youth in...challenging circumstances" (2018, para 1). Their mission is to "seek out and highlight fiction and non-fiction titles...of high-interest and appeal to youth, aged 9-21, that reflect marginalized and/or street culture" (2018, para 3). In the Margins not only provides an excellent resource list on which to draw for collection development, they also encourage youth reviewers in order to facilitate authentic assessments and donate many highinterest titles to juvenile detention facilities.

Several community groups also contribute directly to sustaining collections. Books to prisoners programs emerged in the 1970s. The Urbana-Champaign Books to Prisoners (B2P) is an active example. B2P an Illinois-based community organization that aims "to provide books to inmates" by redistributing donated books, "to offer a venue for inmates to tell their own stories," and to educate their community about prisons (2018, n.p.). While B2P focuses primarily on responding to requests to send books to incarcerated adults, they receive many donations. Extra materials, those that do not match interests of adult readers, are sold at book sales to support the costs of operating the program, primarily mailing costs. B2P has long supported our efforts to provide reading materials for youth by allowing us to review and take books from the extra materials they accrue on a regular basis before they are selected for sale.

LGBT Books to Prisoners is another example of an organization that provides critical services in this realm. Located in Madison, WI, it is "a trans-affirming, racial justice-focused, prisonabolitionist project" that "send(s) books to incarcerated LGBTQ-identified people across the country" (2018, para. 1).

In addition to working with organizations that redistribute books, we also acquire materials for the collection through direct donations from local public, school, and special libraries. Librarians working in these organizations who are aware of JDC library efforts and limited funding look out for materials to contribute, such as galleys, discards, and donations. Local individuals, especially librarians and library students, who assist as volunteers in essential areas such as weeding, repairing materials, and project workdays, augment organizational support. Over the course of our involvement, we have also received donations directly and secured grant funding to support initiatives. Creating occasional wish lists that can be shared online with community members has also proved effective in terms of raising awareness and generating funds to purchase new materials. The titles we request are drawn from book lists, such as those created by WNDB and In the Margins, reviews, and, most importantly, the feedback and recommendations provided by youth.

\section{Programs}

Youth themselves are essential contributors to the success of the library. This manifests in a number of ways. For example, they provide peer reviews and share details about high-interest titles, authors, and genres, and encourage further development; when possible, they also actively engage in programs. One popular program links them to outreach efforts of local public libraries. During summer, when they are not in classes, youth participate in summer reading and greatly enjoy the new books they sometimes receive as prizes for achieving certain goals.

To help isolated youth, especially those who have been incarcerated, it is important to look for ways to build connections with the community. Linking with the public library to offer summer reading programs helps to reduce isolation and access barriers. This is also a pathway to 
facilitating more connections after release. Exposure to public library programming may encourage future interest and engagement.

Within the JDC, the availability of programming is dependent on adult supervision. In the case of library services, programs are reliant on volunteers to facilitate activities. In our experience, youth seek out, engage in, and appreciate varied opportunities for creative expression. In this vein, The Beat Within provides a robust framework of support in consistently producing thoughtful and bold works emphasizing youth voices. The Beat was founded as a non-profit in San Francisco and printed its first publication in 1996 following the murder of rapper Tupac Shakur, when young people sought ways to express their intense feelings of loss. Today, staff and volunteers produce weekly publications written by and for incarcerated youth. The Beat Within's mission "encourages literacy, self-expression, ...critical thinking skills, and ...supportive relationships with adults and [the] community" (2018, para. 1). They "are committed to being an effective bridge between youth who are locked up" and communities that "support their progress towards a healthy, non-violent, and productive life" (2018, para. 1).

The Beat is a valuable resource that encourages youth to understand themselves as belonging to a community of writers. From this experience, youth can grow and express their talents in other venues. After having their work published in The Beat, youth have gone on to author selfpublished novels, participated in a variety of national writing contests, and produced zines.

Our model, based on an iterative process and cycles of feedback, has been important to the success of the creative writing programming we have offered. Volunteers on the outside and incarcerated adults provided weekly feedback to youth writers at the detention center. Feedback from dedicated incarcerated adults who could reflect on youth writing from their own lived experiences was especially meaningful to the writers.

Writing support helps to develop positive emotional connections and enables sharing life experiences in terms of similarities and differences. It is critical to encourage pathways to facilitating exchange as part of this programming. Youth often mention that they never had positive feedback on the work they had written. Not only did community members who served as reviewers validate youth perspectives and experiences, but they also learned to think anew about social issues that youth confronted in their communities. This kind of relationship building can break down the walls that keep youth invisibilized and provides a venue for their perspectives to be heard and valued.

Involvement in programs fosters positive relationships between youth in custody and other incarcerated individuals and non-incarcerated community members. This may include regular volunteer visits and special guests. In our programs, many individuals have participated, including librarians, peer mentors, college students, scientists, gardeners, yoga teachers, artists, and others offering critical community resources.

Occasionally, we have also found funding to bring in authors to meet with youth. In addition to book group activities and writing workshops, author visits are powerful ways for youth to experience focused and in-depth engagement. In our experience, these events are most successful when they are designed to foster intimate writer-to-writer connections. When youth are positioned as writers, readers, and thinkers interacting with authors, they are empowered as contributors rather than treated as passive receivers. Youth may introduce speakers, share their own work with speakers, ask questions about the writing process, and debate critical 
social issues presented in reading materials by drawing upon their own life experiences.

One final program we have offered successfully is digital music production. While there is free and open source content available, this activity can be more challenging to run because of the special equipment and permissions that may be required. The benefits are significant, however. Youth are highly engaged as content creators. They become equipped with valuable skills that can be harnessed in greater depth upon release; similar to summer reading programs, digital music production may be linked to public library programming that fosters continued engagement with library services after release.

\section{Toward Brighter Futures}

It is important that library services for young people in custody be considered within an expansive framework that can account for the ways in which many young people are targeted for failure. While racial and class inequality are the constitutive elements to the alarming U.S. incarceration rates, these issues are not limited to the United States. Progressive librarians around the world are called to meet the information needs of young people affected by systems of oppression. We must not lose sight of the way in which these structures undermine our efforts to offer equitable library support to youth. Our patchwork approach is not proposed as a solution to these problems. It is a concerted commitment to keep trying even as institutions continue to fail youth. Our efforts are invested in working toward brighter futures and more robust alternatives, alternatives that young people across the country and around the globe who find themselves entangled in systems of injustice deserve. There is much more to do.

\section{References}

Alexander, M. (2010). The new Jim Crow: Mass incarceration in the age of color blindness. New York: New Press.

American Civil Liberties Union (ACLU). (2018). America's addiction to juvenile incarceration: State by state. Retrieved from https://www.aclu.org/issues/juvenile-justice/youthincarceration/americas-addiction-juvenile-incarceration-state-state

Austin, J. (2018). Restorative justice as a tool to address the role of policing and incarceration in the lives of youth in the United States. Journal of Librarianship and Information Science, Sage OnlineFirst.

The Beat Within. (2018). About us. Retrieved from http://www.thebeatwithin.org/about-us

Cacho, L. M. (2012). Social death: Racialized rightlessness and the criminalization of the unprotected. New York: New York University Press.

Davis, A. Y. (2003). Are prisons obsolete? New York: Seven Stories Press.

Fine, M., \& Ruglis, J. (2009). Circuits and consequences of dispossession: The racialized realignment of the public sphere for U.S. youth. Transforming Anthropology, 17(1), 2033. 
Higgins, N. (2017). Get inside: Responsible jail and prison library service. Chicago: Public Library Association.

In the Margins. (2018). 2018 In the Margins press release. Retrieved from https: / / inthemarginssite.wordpress.com/2018/02/14/749

LGBT Books to Prisoners. (2018). Mission. Retrieved from https: / / lgbtbookstoprisoners.org

National Institute of Corrections. (2015). Policies and procedures for juvenile facilities. Retrieved from https://nicic.gov/policies-and-procedures-juvenile-facilities

Sweeney, J. (2011). Literacy: A way out for at-risk youth. Santa Barbara, CA: Libraries Unlimited.

Tatum, A. W. (2006). Engaging African American males in reading. Educational Leadership, 63(5), 44-49.

Tsing, A. L. (2015). The mushroom at the end of the world: On the possibility of life in capitalist ruins. Princeton: Princeton University Press.

Urbana Champaign Books to Prisoners. (2018). UC books to prisoners - A project of the UCIMC. Retrieved from http://www. books2prisoners.org

Wagner, P. \& Sawyer, W. (2018). Mass incarceration: The whole pie 2018. Prison Policy Initiative. Retrieved from https: //www. prisonpolicy.org/reports/pie2018.html

Washington, J. (2018, July 31). What is prison abolition? The movement that is trying to think beyond prisons as a tool to solve society's problems. The Nation. Retrieved from https: / / www.thenation.com/article/what-is-prison-abolition

We Need Diverse Books (WNDB). (2018). About WNDB. Retrieved from https: //diversebooks.org/about-wndb/

Dr. Rae-Anne Montague (raemontague@gmail.com) has many years of experience as a teacher, librarian, and library educator. She currently works at Chicago State University as a member of the Information Studies faculty. Her research interests center on learning communities and social justice.

Joe Coyle (joe.a.coyle@gmail.com) has provided library services for young people in custody since 2009. He is currently a doctoral student in Anthropology at the University of Illinois at Urbana-Champaign. His doctoral research focuses on LGBT Pentecostals in Brazil and shifting forms of religious, national, and sexual belonging. 